\title{
A influência dos grupos amino e hidroxila no arranjo supramolecular de duas trimetoxi-chalconas
}

\author{
Igor Dalarmelino Borges $^{1(\mathrm{IC})^{*}}$, Vitor Santos Duarte ${ }^{2(\mathrm{PG})}$, \\ Ricardo Rodrigues Ternavisk ${ }^{2(\mathrm{PG})}$, Hamilton Barbosa Napolitano 1,2(PQ). \\ igor_dalarmelino@hotmail.com \\ ${ }^{1}$ Centro Universitário de Anápolis (UniEVANGÉLICA), Anápolis, GO, Brasil. \\ ${ }^{2}$ Universidade Estadual de Goiás, Câmpus Anápolis de Ciências Exatas e Tecnológicas - Henrique \\ Santillo, Anápolis, GO, Brasil.

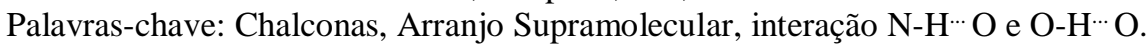

Chalconas são compostos orgânicos que podem ser obtidos pela extração de fontes naturais ou por meio de síntese química ${ }^{1}$. Tais compostos são amplamente estudados devido seu potencial de aplicação biológica sendo descritos na literatura como anti-inflamatório, antifúngica, antiprotozoários ${ }^{2,3}$, antimalarial, antioxidante, dentre outras ${ }^{4}$. A estrutura base das chalconas possui uma cadeia insaturada de três carbonos que são ligados em suas extremidades a um anel aromático. ${ }^{5}$ Estruturas semelhantes indicam potencialidades à propriedades semelhantes, contudo na presença de diferentes grupos funcionais em estruturas similares podemos ter alterações significantes no arranjo molecular. O entendimento estrutural desses compostos nos auxilia na compreensão do arranjo supramolecular bem como na interpretação das propriedades físicas, químicas e biológicas. A metodologia cristalográfica ${ }^{6}$ descreve os aspectos estruturais e elucida as interações presentes no empacotamento. Para as duas chalconas apresentadas analisamos a influência dos grupos amino e hidroxila para o arranjo supramolecular. Na chalcona 1 temos parte da planaridade sendo estabilizada por uma interação intramolecular do tipo $\mathrm{N}-\mathrm{H} \cdots \mathrm{O}$ e para a chalcona 2 temos como auxilio na planaridade uma interação intramolecular do tipo $\mathrm{O}-\mathrm{H} \cdots \mathrm{O}$, como ilustrado na figura 1 .

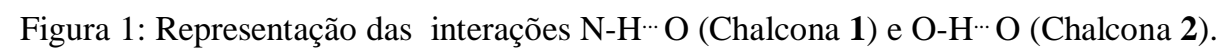

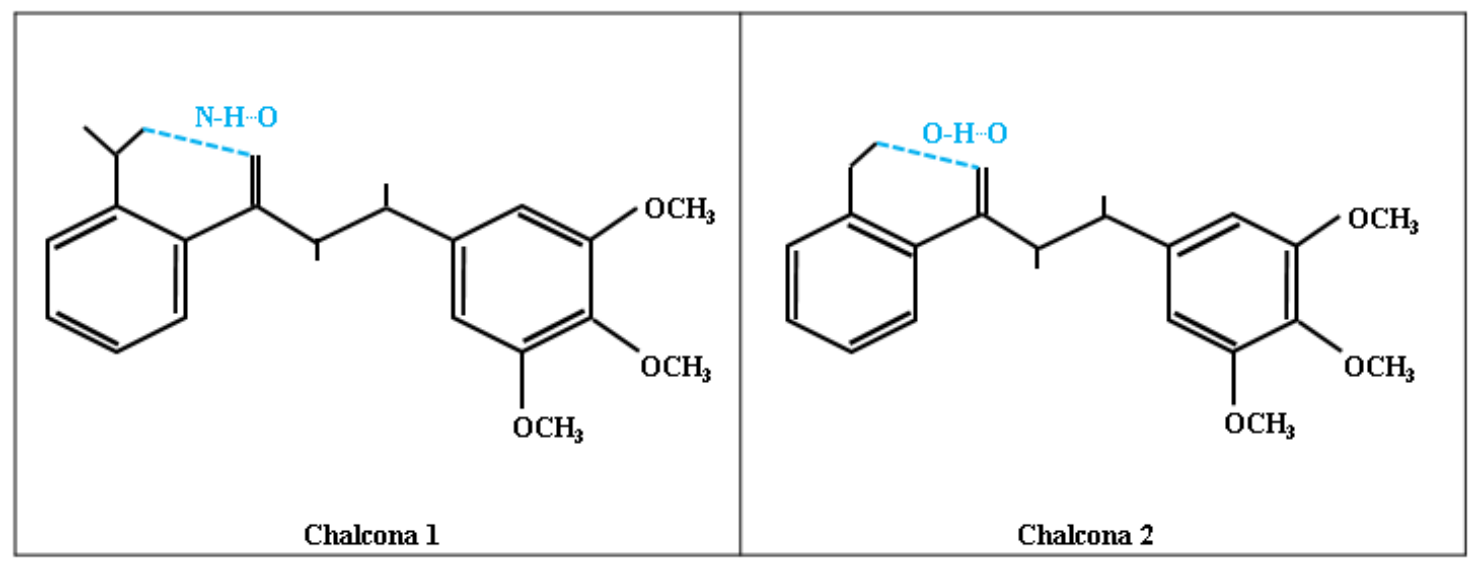


Na chalcona 1, a interação $\mathrm{N}-\mathrm{H}^{\cdots \cdots} \mathrm{O}$ possui os seguintes parâmetros;

\begin{tabular}{cccc}
\hline $\mathbf{d}(\mathbf{D}-\mathbf{H}) \AA$ & $\mathbf{d}(\mathbf{H} \cdots \mathbf{A}) \AA$ & $\mathbf{d}(\mathbf{D} \cdots \mathbf{A}) \AA$ & $\mathbf{d}(\mathbf{D}-\mathbf{H} \cdots \mathbf{A})\left({ }^{\circ}\right)$ \\
\hline 1,017 & 1,844 & 2,621 & 130,40 \\
\hline
\end{tabular}

Enquanto que na chalcona 2, a interação $\mathrm{O}-\mathrm{H} \cdots \mathrm{O}$ possui os parâmetros;

\begin{tabular}{cccc}
\hline $\mathbf{d}(\mathbf{D}-\mathbf{H}) \AA$ & $\mathbf{d}(\mathbf{H} \cdots \mathbf{A}) \AA$ & $\mathbf{d}(\mathbf{D} \cdots \mathbf{A}) \AA$ & $\mathbf{d}(\mathbf{D}-\mathbf{H} \cdots \mathbf{A})\left({ }^{\circ}\right)$ \\
\hline 0,944 & 1,643 & 2,523 & 153,40
\end{tabular}

Notamos que para a interação $\mathrm{O}-\mathrm{H}^{\cdots} \mathrm{O}$ na Chalcona 2 tem-se uma menor distância quando comparada a interação $\mathrm{N}-\mathrm{H}^{\cdots} \mathrm{O}$ da Chalcona 1 e também tem-se um ângulo mais próximo de $180^{\circ}$ para a interação $\mathrm{O}-\mathrm{H} \cdots \mathrm{O}$. A característica de interação mais intensa pode ser avaliada pelos parâmetros geométricos, e as diferenças para o arranjo supramolecular da estrutura podem ser assim analisadas, contribuindo para o entendimento conformacional e interacional da estrutura. . Um estudo sobre a topologia molecular pelos métodos de Teoria Quântica de Átomos em Moléculas (QTAIM) será realizada para identificar os níveis energéticos das interações observadas no arranjo supramolecular de ambas chalconas.

\section{Agradecimentos}

Os autores agradecem a Coordenação de Aperfeiçoamento de Pessoal de Nível Superior (CAPES) pelo apoio financeiro.

\section{Referências}

1. Patil, C. B., Mahajan, S. K. \& Katti, S. A. Chalcone: A versatile molecule. J. Pharm. Sci. Res. 1, 11-22 (2009).

2. Nowakowska, Z. A review of anti-infective and anti-inflammatory chalcones. Eur. J. Med. Chem. 42, 125-137 (2007).

3. Silva, W. A. et al. Biological and structure-activity evaluation of chalcone derivatives against bacteria and fungi. J. Braz. Chem. Soc. 24, 133-144 (2013).

4. Singh, P., Anand, A. \& Kumar, V. Recent developments in biological activities of chalcones: A mini review. Eur. J. Med. Chem. 85, 758-777 (2014).

5. Devia, a. C., Ferretti, F. H., Ponce, C. a. \& Tomas, F. Conformational equilibrium and intramolecular hydrogen bond of $4 \mathrm{H} \mathrm{X}$ and $4 \mathrm{X}$ substituted $2 \mathrm{H}$ ( OH ) chalcones. Journalof Mol. Struct. 493, 187-197 (1999).

6. William B. Fernandes, Hamilton B. Napolitano, C. N. \& Lariucci, F. T. M. \& C. Aplicações Tecnológicas da Metodologia Cristalográfica. Rev. Process. químicos 4, 19-32 (2010). 